\title{
Espacialidades
}

\section{A ARTE CONSTRUINDO IDENTIDADE(S) NA COLÔNIA SANTA ISABEL (1931-1982).}

Art building identity (s) in the Colônia Santa Isabel (1931-1982).

André Luiz de Jesus Bueno ${ }^{1}$

Polyana Aparecida Valente ${ }^{2}$

Artigo recebido em: 08/08/2020.

Artigo aceito em: 15/01/2021.

RESUMO:

O presente trabalho tem por objetivo fomentar as discussões sobre as manifestações artísticas ocorridas na Colônia Santa Isabel (1931-1982). A Colônia foi o primeiro sanatório edificado em Minas Gerais, idealizadopelo saber médico, e orientado pelas conferências profiláticas de isolamento aos acometidos pela hanseníase. Neste artigo vamos discorrer sobre como os asilados construíram identidades artísticas de resistência e pertencimento durante a experiência de segregação terapêutica. A escolha pelo tema das manifestações artísticas justifica-se pelas lacunas historiográficas em torno dessa discussão. Para operar a análise, partimos da análise documental e de entrevistas pertencentes ao acervo da Fundação Artístico Cultural de Betim FUNARBE no desenvolvimento do Inventário Participativo da Colônia.

PALAVRAS-CHAVE: Arte; Colônia Santa Isabel; Hanseníase.

\section{ABSTRACT:}

This work aims to encourage discussions about the artistic manifestations that took place in Colônia Santa Isabel (1931-1982). The Colony was the first sanatorium built in Minas Gerais, idealized by medical knowledge, and guided by prophylactic conferences to isolate those affected by leprosy. In this article, we will discuss how asylum seekers have built artistic identities of resistance and belonging during the therapeutic segregation experience. The choice for the theme of artistic manifestations is justified by the historiographic gaps surrounding this discussion. To operate the analysis, we started from the documentary analysis and interviews belonging to the collection of the Fundação Artístico Cultural de Betim - FUNARBE in the development of the Colonial Participatory Inventory.

KEYWORDS: Art; Colônia Santa Isabel; Hansen.

1 Mestrando em Educação pela Universidade Federal de Minas Gerais. Historiador da Fundação Artística Cultural de Belém. Lattes: http://lattes.cnpq.br/4803483811967569. E-mail: andrebuenohist@gmail.com

2 Pós-doutoranda da Fiocruz no campo da Saúde Coletiva. Professora da Universidade do Estado de Minas Gerais (UEMG) em Ibirité. Lattes: http://lattes.cnpq.br/3885781523666600. E-mail: polyvalente84@gmail.com 


\section{Introdução}

A Colônia Santa Isabel surgiu no bojo das transformações urbanas, sanitárias e política do advento da República e do modernismo no Brasil. A política sanitarista presente neste espaço foi fruto de conferências profiláticas ocorridas nas primeiras décadas século XX. Tal necessidadeemergia de um país dominado por epidemias e por um sistema de saneamento precário, que na visão dos republicanos retardava o seu desenvolvimento. Neste contexto o saber médico-científico legitimou o isolamento das pessoas consideradas não aptas ao convívio social, como era o caso dos atingidos pela lepra e pela tuberculose.

No caso da lepra, sabia-se que era uma doença contagiosa e que representou grande risco para sociedade, pois ainda não se alcançara avanços expressivos em sua cura.Salienta Chaves (2011) que o tratamento da lepra foi um assunto à parte na reformulação dos serviços sanitários. A questão dos leprosários tinha estreita relação com a imagem social que se edificou em torno da doença. As construções distantes, baseadas em uma concepção de isolamento dos doentes, foram acompanhadas de uma série de medidas de caráter profilático, com vistas a conter a enfermidade.

De maneira geral, estabeleceu-se até a década de 1950, um estilo de vida adaptado em colônias de isolamento quefundouuma estrutura socialpeculiar baseada na exclusão e no desconhecimento da doença. Como mostra Carvalho (2012), o objetivo do isolamento era proteger as pessoas sadias da sociedade e causar a sensação de que os internos ficariam bem e protegidos dentro das colônias. Tal mecanismo de isolamento, estava presente em quase todos os estados brasileiros, pois tratava-se de um projeto de nação educada e saudável.(ROCHA e VEIGA, 2011). Pensando essa estrutura, Matos, assim descreve a organização espacial da colônia:

(...) é possível dividi-la em três áreas: a zona dos doentes (leprosário, com os pavilhões de diversões, refeitório, pavilhão para crianças, para moças, para mulheres,para homens, casas geminadas, casas isoladas, intendência, hospital de homens, hospital de mulheres, igreja, necrotério, praça de esportes, cemitério, caixa beneficente; dispensário ou local de distribuição de remédios); A zona intermediária (pavilhão de recepção, pavilhão de observação, parlatório ou local de visitas e a cozinha geral) e a zona dos 
trabalhadores da saúde (administração, residências do diretor, dos médicos e demais funcionários, almoxarifado, garagem, padaria, escola, casa das irmãs, capela farmácia, laboratório e usina de força). (MATOS,s.d. p.43).

$\mathrm{Na}$ teoria e na concepção dos idealizadores da Colônia traçou-se um projeto "perfeito" no modo de acomodar, amortecer e cuidar dos doentes de Santa Isabel. No entanto, podemos indagar se essa organização planejada correspondia aos anseios e necessidades da população asilada que fora retirada dos seus territórios e dos seus círculos de sociabilidade, de outro modo podemos pensar como as diferentes subjetividades ali presentes tencionaram a configuração do espaço, a construção do sentimento de pertença ao universo da colônia.

Desta forma, nas duas primeiras décadas do seu funcionamento, a Colônia foi marcada por constantes transformações na sua estrutura e organização para ajustar as necessidades da emergente sociedade. As adaptações, resistências, símbolos e estratégias de pertencimento, passam desde a modificação física dos espaços, como pela questão da alimentação, das rotinas diárias, atividades esportivas, sociabilidades diversas, das quais destacamos as manifestações artísticas e culturais.Essas manifestações configuram-se gradualmente, com a chegada de novos internos,ressignificando o lugar e construindo uma nova sociedade dentro e nos arredores da Colônia Santa Isabel.

Para o desenvolvimento do trabalho proposto utilizamos as fontes e resultados daspesquisas desenvolvidas pela Fundação Artístico cultural de Betim FUNARBE, em 2010, na promoção do inventário Participativo na Regional de Citrolândia, que resultou na construção do "Caderno da Memória"3". Utilizamos também as entrevistasrelacionadas à identidade social de Santa Isabel realizadas em 2012, com antigos asilados de Santa Isabel.

\footnotetext{
3 O Caderno da Memória 4 - Patrimônio Cultural da Regional Citrolândia, foi publicado em 2010 pela Fundação Artístico e Cultural de Betim -Funarbe, com o propósito de publicitar o conhecimento histórico da cidade de Betim e de suas regionais. Tal trabalho abordou em seu contexto, contribuições sobre a ocupação, formação e desenvolvimento da Regional Citrolândia.
} 


\section{A Colônia Santa Isabel}

Instituída como um marco fundador da campanha contra a lepra em Minas Gerais (CARVALHO, 2012).Santa Isabel foi criada pela lei no 801 de 22/09/1921 e ganhou corpo através do Decreto no 6.038 de 21/03/1922, que desapropriou, a título de utilidade pública, os terrenos, mananciais e benfeitorias da Fazenda do Motta, pertencentes ao município de Santa Quitéria. A pedra fundamental foi lançada em 12/10/1922. A colônia, propriamente dita, recebeu seus primeiros habitantes em 23/12/1931 (MATOS, 2004).

A escolha do local que sediou a Colônia contou com a influência de vários fatores dos quais destacamos, o distanciamento da capital mineira. A acessibilidade pela Estação Ferroviária Carlos Chagas, localizada na cidade de Mário Campos, o que facilitava o contato e a manutenção do Estado e o embarque e desembarque de pessoas e mercadorias. Outro fator importante eraà presença de terra fértil para implantar uma cultura de subsistência na Colônia. Destaca-se também a presença de barreiras naturais, como o Rio Paraopeba e o Córrego Bandeirinha que dificultava nas fugas. Por outro lado, a necessidade de recursos hídricos, como abastecimento e geração de energia elétrica, também auxiliava na manutenção desta pequena sociedade edificada sobre as ruínas da antiga fazenda do Motta.

A construção da Colônia contou com o consórcio de diversas cidades mineiras e do governo do estado, interessados em "tratar" os acometidos pela doença. O nome de alguns pavilhões, inclusive, são fontes importantes para identificar os municípios interessados no envio de doentes, como Juiz de Fora e Muriaé. Tais edificações tinham por objetivo compor o conjunto urbano daquela sociedade (GONTIJIO, Vol.1). 
Figura 1 - Planta da Colônia Santa Isabel

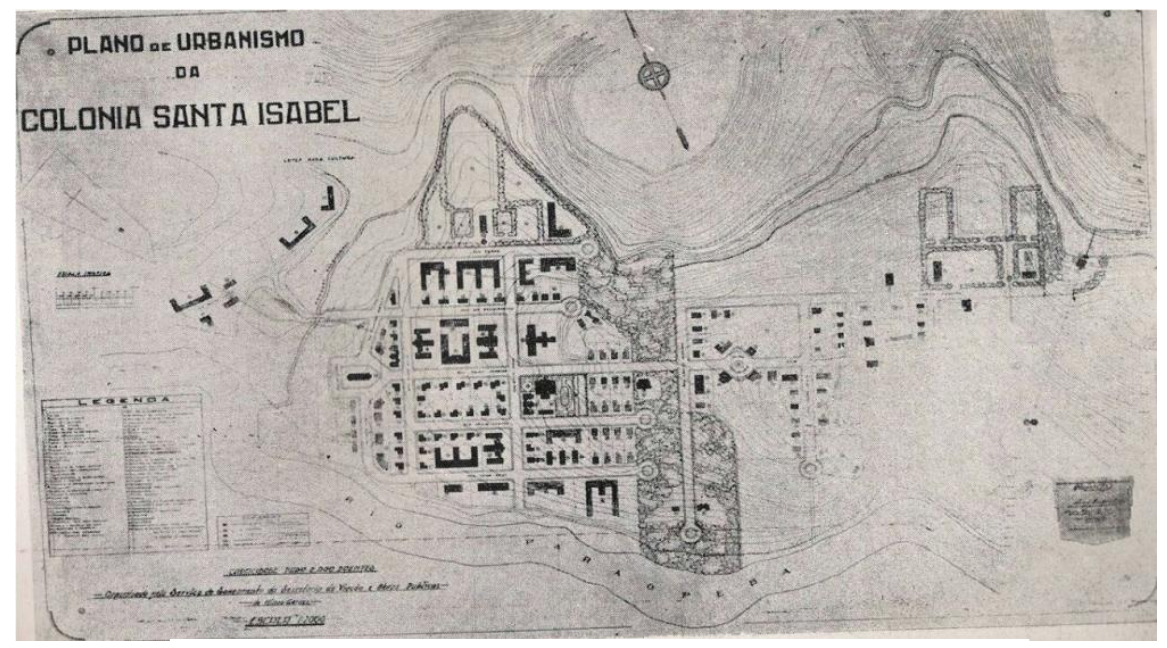

Fonte: Acervo Funarbe.

Findada a construção da Colônia no ano de $1931^{4}$, as prefeituras executaram uma espécie de "limpeza", enviando para o recém construído espaço de saúde os seus cidadãos atingidos pela lepra (GONTIJIO, Vol.1).

A colônia foi projetada pelo engenheiro civil Lincoln Continentino ${ }^{5}$ e pelos médicos Antônio Aleixo ${ }^{6}$ e Samuel Libânio ${ }^{7}$. Esta união entre o saber médico e a engenharia buscava originar um ambiente hospitalar com edificações amplas e arejadas e arruamentos largos e bem distribuídos, levando em consideração as concepções sanitárias da época. Para, além disso, como afirma Carvalho (2012) a construção de colônias autossuficientes e com algum padrão de conforto funcionava como contrapartida do Estado ao privar o indivíduo de sua liberdade. Nas palavras da autora "a perspectiva era de que, apesar de isolado, o indivíduo pudesse continuar vivendo como se estivesse na sociedade" (CARVALHO, 2012)

Como podemos ver na defesa do seu projeto:

\footnotetext{
${ }^{4}$ GONTIJO, Gramont, A História da Colônia Santa Isabel, Vol.1. Betim, manuscrito, s.d.

${ }^{5}$ Inspetor de Engenharia Sanitária do Estado de Minas Gerais.

${ }^{6} \mathrm{O}$ pioneiro moderno da campanha contra a lepra em Minas Gerais.

7 Então diretor de higiene de Minas Gerais entre 1918-1920, inicia as medidas de profilaxia, cuja expressão maior se encerra na lei $\mathrm{N}^{\circ} 801$, de 2 de setembro de 1921, criando a Colônia Santa Isabel, sendo sua pedra solenemente lançada em 12 de outubro de 1922.
} 
O engenheiro sanitarista caminha no sentido de criar condições para o tratamento da moléstia através de práticas científicas, a partir de uma visão positiva do mundo. Nesse momento o serviço hospitalar torna-se o coração, o motor de todas as engrenagens da instituição, através do qual os pacientes alcançariam a cura e o retorno à sociedade. (FUNARBE, 1998, p. 30)

Tal estrutura se equiparou a um laboratório, porém a céu aberto. O plano arquitetural facilitava a vigilância em relação às fugas; em uma ambientação carcerária que seguia as normas estabelecidas pelas conferências profiláticas e pela moderna engenharia.

O plano consolidou a existência de três zonas distintas em Santa Isabel. A zona sadia, que se iniciava pelo antigo portal, onde se localizavam as residências dos funcionários, médicos, casa do diretor e as residências dos religiosos. Em suma, residiam nesta área somente as pessoas sadias. A segunda zona era a intermediária, onde se localizavam o pavilhão de observação, laboratório, estufas de desinfecção, casa de máquinas e parlatório. Esta área tinha como objetivo principal o diagnóstico e a seleção de pacientes conforme ao estágio que se encontrava com a doença. Por fim, a zona doente, conhecida como o coração da colônia. Espaço destinado às pessoas solteiras, com a seguinte divisão: pavilhões de mulheres, de homens e de crianças. Para os casais, havia casas geminadas.

Havia ainda um campo de futebol, necrotério, sede da administração, refeitório geral, pavilhão de diversões, a igreja matriz de Santa Isabel entre outros: “inspiradas nas experiências europeias anteriores, a lógica urbana seguia a lógica do tratamento, materializado num rígido zoneamento funcionalista" (ROCHA e VEIGA, 2011). O Pavilhão Juiz de Fora, por exemplo, também nomeado Cine Teatro Glória ou Pavilhão de Diversões, possuía três partições: Cassino, Cinema e Salão de Bailes, onde se apresentavam grupos de jazz, bandas e coral. Além disso, o esporte também se fixou na vida da Colônia com a criação de times de futebol e basquete nos gêneros masculino e feminino. 


\section{Espacialidades}

Foto 1 - Vista da Colônia Santa Isabel.

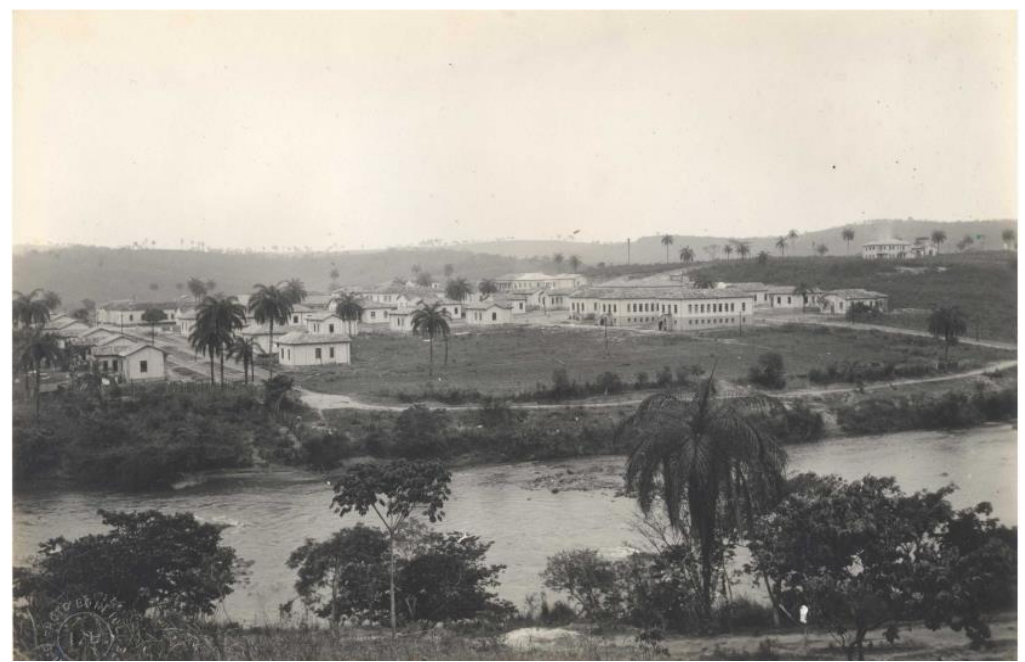

Fonte: Centro de Memória da Medicina de Minas Gerais

(Cememor-MG)

No início de seu funcionamento, as várias identidades que foram encaminhadas para a colônia carregadas pelo flagelo da doença, contribuíram para a construção de uma sociedade e formulação da identidade do que seria o morador daquele espaço:

É o próprio do doente que, considerado pela desgraça que lhe cai sobre os ombros, pensa no perigo de sua presença no meio familiar que desde logo procura preservar, e assim é levado a tomar resoluções que o ponham desde logo, ao abrigo do perigo e das prevenções sociais. (DINIZ, 1961, p. 295).

Desta forma, a presença de um doente na família era um estigma de condenação de seus integrantes perante toda a sociedade. Como salienta Carvalho (2012), sem dúvidas essa experiência gerou tramas e perdas ao asilado. Ou seja, ao entrar na colônia os asilados tiveram que reaprender a viver, a construir novas formas de sociabilidade. Para administrar os conflitos e organizar essa "nova sociedade" os regimentos internos e administrativos eram importantes reguladores.

O isolamento separou dos laços familiares chefes de família, mães do lar e crianças. E, pelo fato destes estarem ligados a outras pessoas, a sociedade se encarregou de excluí-los também de seu convívio. Assim construíram novos laços, 
identidades e espaços de sociabilidade, ressignificando seu lugar no mundo e na sociedade. Realocando também, muitas vezes seus familiares.

Segundo Assis,

esta situação expulsou do convívio social os hansenianos e suas famílias que foram invadindo terrenos próximos às colônias e se estabelecendo no local. [...] O Estado tentou evitar que as famílias fossem morar nas proximidades, mas o estigma social foi mais forte, levando as pessoas a lutar para ficarem próximas dos parentes. (ASSIS, 1996, p.43).

É a partir deste processo, que surge no entorno da colônia, o povoado do Limas, atual Citrolândia.A relação social dos antigos internos com seus familiares, tanto no processo de segregação interfamiliar como no processo de expulsão de seus familiares pela ligação e proximidade com um hanseniano desencadeou a ocupação da localidade,que sema mesma infraestrutura empregada pelo Estado na Colônia, forçou a comunidade a se organizar e se desenvolver de forma sócio cultural e economicamente. (FUNARBE, 1998).

Em termos de religiosidade, a primeira década do funcionamento de Santa Isabel é marcada pela presença do catolicismo ${ }^{8}$ representado pela atuaçãomissionária e assistencial das irmãs do Monte Calvário e dos frades franciscanos aos internos. O assistencialismo proposto era visto como fator de elevação moral, de estímulo, higiene, disciplina e economia. A presença dos religiosos era considera um dos mais importantes serviços prestados aos doentes. (DINIZ, 1933). Por fim, na década de 1940, acontece à ruptura da hegemonia católica, com a internação de adeptos de seguimentos protestantes e do espiritismo kardecista, tais agremiações na decorrente década, também ganharam espaço compondo assim, a sociedade de Santa Isabel.

\footnotetext{
${ }^{8}$ Com efeito, atese de Gisele Porto Sanglard, "Entre os salões e o laboratório: filantropia, mecenato e práticas científicas - Rio de Janeiro, 1920-1940", 2005. Destaca a relação e atuação histórica da Igreja Católica na assistência dos mais pobres e doentes.
} 


\section{Espacialidades}

Além da presença do Estado e da religião, como veremos a seguir, a arte sem dúvida foi uma importante aliada para que os internos pudessem viver o isolamento com mais leveza. Como mostra Carvalho (2012) havia uma intensa vida cultural dentro e fora dos espaços de entretenimento no leprosário. A presença de artistas (os mais variados) criava uma atmosfera artística por toda a colônia.

Assim, apresentamos a diante diferentes manifestações artísticas experimentadas na Colônia Santa Isabel. Tais dados aqui explorados são oriundos do Inventário participativo realizado pela Fundação Artístico Cultural de Betim em 2010, que fomentou a publicação do Caderno da Memória da Regional Citrolândia. Especialmente das entrevistas concedidas por José Bueno Filho e Sebastião Martins Botelho.

\section{A arte musical}

A arte musical surge na colônia como a possibilidade de adaptação a nova vida. Segundo Gontijo (s.d) “A colônia Santa Isabel embora, ter sido taxada, e noticiada em vários jornais como a cidade dos mortos vivos, era mortasó no preconceito" (GONTIJIO, Vol.1., s.d, p.21). A música se mostrou como um canal possível de diálogo dos habitantes da colônia com o mundo exterior.

É importante ressaltar o papel da Caixa Beneficente, como um órgão coordenado pelos próprios internos, que tinha como objetivo administrar as doações e serviços daantigaColônia. Era uma entidade responsável pelo fomento de vários grupos musicais de Santa Isabel. Desta forma, bandas de música foram constituídas para o acompanhamento dasfestividades, como o dia da Independência e as comemorações dos festivais e dos times de futebol da Colônia. Além disso, os grupos de Jazz e Choro animavam as noites da boemia. 
Foto 2: Grupo de Jazz da Colônia Sta. Isabel Década de 60.

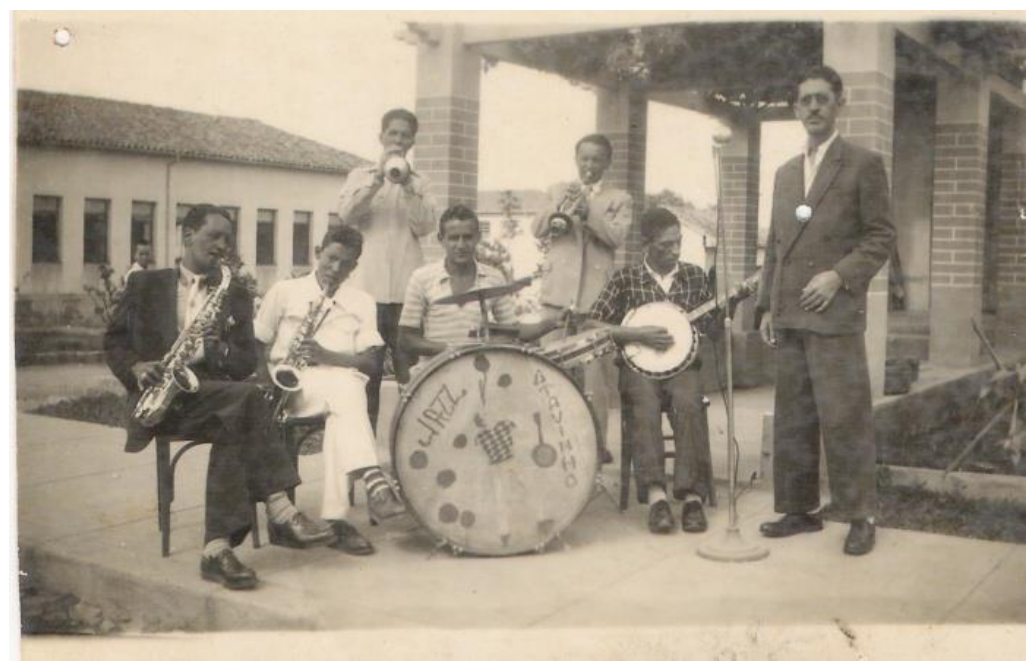

Fonte: Acervo Memorial José Avelino.

Entre os músicos da Colônia, destacou-se o Maestro José Carlos da Piedade. Natural de Patrocínio, autor de "Saudades do Matão", permaneceu em Santa Isabel em um curto espaço de tempo até sua morte em 1939.9 Juntamente com outros músicos, criou a Lira Três de Outubro no início dos anos 1930. Esta composição, mais tarde, passou a se chamar Euterpe Carlos Gomes, a primeira manifestação artística da Colônia. Outro importante membro dessa linhagem foi o Coral Tangarás de Santa Isabel. Criado em 1936, com o nome de "Coro de Santa Cecília", como resultado da junção de músicos recém-chegados no hospital Colônia. O coral foi criado em caráter religioso para a inauguração da Matriz de Santa Isabel: “O coro interpretava em latim, com base em fontes como a harpa de Sião e o Lecionário Santa Cecília, acompanhado do harmônio executado por Isaura Nunes” (FUNARBE, 2010, p.79). Com a chegada do músico Paulo Luiz Domingos na década de 1960, instrumentos de corda e cavaquinhoforam adaptados ao coro.

Um marco para a vida do Coro, ocorreu em 1985, quando Frei Francisco Vander Poel, "Frei Chico”, assumiu a regência, transformando-o em Coral Tangarás e anexando em seu repertório a música popularbrasileira. O Coral Tangarás surgiu

\footnotetext{
${ }^{9}$ Dispensário Souza Gomes - Ficha Social no 2.692 de Lepra.
} 
para preencher as lacunas litúrgicas das celebrações eucarísticas. Carvalho(2007) assim relata o significado do nome Tangarás:

\begin{abstract}
“Tangará é um pássaro hoje em extinção curiosamente só cantava em bando, tem um regente e todos obedecem, quando estão cantando nada faz parar a cantoria, enquanto não termina a melodia. O regente pula de um galho para outro, abaixa acabeça, abre o bico, outra hora suspende a cabeça, ficando de forma vertical, ginga de cá para lá, bate asas, é uma regência de verdade." (CARVALHO, 2007, p. 231).
\end{abstract}

De acordo com Sebastião Martins Botelho, ${ }^{10}$ "A arte na vida do hanseniano é um lenitivo para as dores dele em um refúgio de paz". É necessário frisar que, em sua individualidade, os antigos internos produziram artes relacionadas à doença. Podemos compreender a arte ali produzida comouma forma de representação da realidade da colônia e do indivíduo, mas, sobretudo como uma forma de esquecer a doença e o isolamento. Para Botelho (2010), os internos expressavam como se estivessem desabafando, transformando sua dor individual em uma dor coletiva, passando-a ao conhecimento da sociedade, retratando histórias, acontecimentos e a própria lepra. Ponderamos, no entanto, que não necessariamente a arte ali produzida remetia a doença, a arte é também uma forma de expressão que libertava e construía outras formas de representação do mundo para além da doença e da colônia. Entendemos a arte como sugeri Bosi (1986) elemento de construção, conhecimento e expressão que une o mundo exterior e interior do artista.

Em algumas obras de expressão musical, os doentes retratavam o destino interrompido pelo estigma da doença:

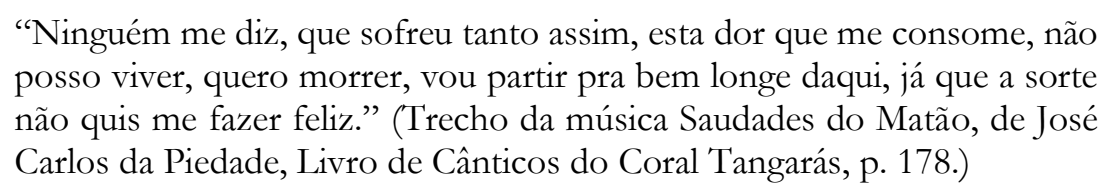

Outro ícone da colônia foi o músico regente Paulo Luiz Domingues, que se internou voluntariamente para se tratar da doença. Autor de músicas religiosas e

\footnotetext{
${ }^{10}$ Entrevista concedida a André Luiz de Jesus Bueno pelo artista e filho de interno, Sebastião Martins Botelho, Betim, 16/02/2012.
} 
populares, assim ele representou a perda da sensibilidade dos dedos na década de 1970 ,

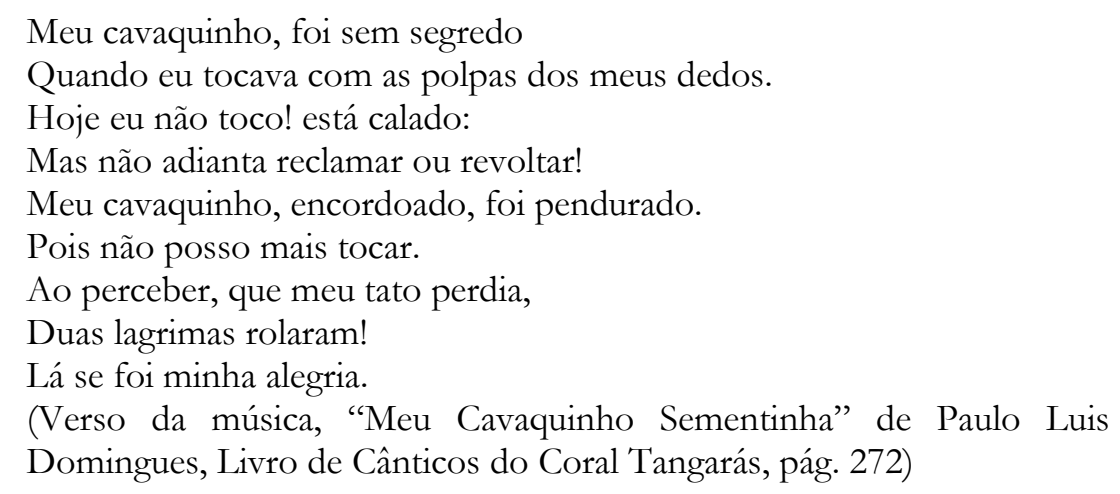

Esta necessidade de contar a realidade era alimentada de uma inspiração gerada pelas dores que cada um trazia em sua bagagem, como forma de desabafo que acabava se tornando arte.Nessa direção, como salienta Tuan (1983)"o espaço tem significado temporal nas reflexões do poeta, na mística da exploração e no drama da migração. O espaço também tem significado temporal ao nível das experiências pessoais do dia-a-dia. A própria linguagem revela a intima conexão entre pessoa, espaço e tempo. (TUAN, 1983, p. 141). Ou seja, a arte produzida na colônia é fruto do sujeito que a produziu em diálogo com o tempo e o espaço no qual estava inserido.

\section{A arte representada pela expressão do corpo.}

Outra expressão de arte importante da antiga Colônia eram os carnavais nos clubes regidos pelas marchinhas. Era um carnaval caricato, com vestimentas próprias de carnavalescos e ambientes enfeitados. Os pioneiros dessa manifestação artística foram Dicalino Cabral e Junior Vilela, nos instrumentos de sopro, Nativo e Silvio Preto, na percussão e, mais tarde, Joaquim Babão, Jonas, Raimundo, Ormideo, Sabiá 
e José Laje, entre outros. Era uma festividade interna que envolvia todos os pacientes, e sob autorização, frequentavam também os moradores do antigo Limas11.

De acordo com entrevista cedida pelo interno José Bueno Filho, em 2012, o carnaval era formado por vários blocos, destacando-se o bloco que saia entre quinze e quatorze horas, que era o das crianças, e outro às dezoito horas, que era formado poradultos. Todo o festejo era apoiado pela Caixa Beneficente que, através das doações, ajudava os internos com os enfeites e fantasias.

Segundo Bueno (2012), após as festividades do Carnaval, dando sequência aos decorridos quarenta dias da quaresma, a queima do Judas, que representava um roubo simbólico, que envolvia os internos em travessuras, nas quais apanhavam objetos e animais das casas da Colônia e levava tudo para perto do boneco de Judas, na Praça da Caixa Beneficente. Esta representação dava-se no sábado de aleluia, após as encenações da sexta feira da paixão. Um grupo de doentes se articulava na madrugada de sexta para sábado para raptar os objetos. Os objetos raptados, após uma série de rituais eram devolvidos. Um desses rituais era a dedicatória, que consistia em uma espécie de testamento dedicado a um interno. A leitura deste testamento ocorria no alto-falante da Caixa Beneficente para os presentes. A estrutura do texto lido era variável, predominando rimas versos, que era elaborado por Eurípides Marques (Bidu). Logo após a leitura, os objetos eram devolvidos e o Judas queimado.

Além dos blocos de carnavais e grupos de encenação da Semana Santa, existiam dois Clubes de Recreação: o Gordurão, designado para as mulheres do pavilhão 24, destinado a morada das chamadas "mulheres de vida" vistas pela comunidadecomo promíscuas, e o Clube da sede da Caixa Beneficente, frequentados pelas moças e os casais residenciais. No que tange aos homens solteiros, eles estavam presentes nas festividades dos dois clubes. (BUENO, 2012)

\footnotetext{
11 Povoado criado na década de 1930 no entorno da Colônia Santa Isabel pelos familiares egressos dos internos, atualmente é conhecido como Citrolândia.
} 
As peças teatrais eram confeccionadas e apresentadas pelos próprios internos, pois "os doentes mesmo com seus corpos carcomidos pelo mal não desanimavam e davam de tudo para esquecer o sofrimento e alegrar os outros irmãos sofredores da Colônia" (GONTIJIO, Vol.1., s.d, p. 29). A comédia e o drama movimentavam e estimulavam a imaginação e emoção dos antigos moradores. O Cine Teatro Glória, considerado o coração cultural da Colônia, era o palco dessas encenações e ensaios. A organização das peças teatrais estava fundamentada em livros doados pela Secretaria de Cultura de Belo Horizonte. A escolha da peça, o início dos ensaios e adaptações, até a apresentação final, demandava um tempo de cerca de 6 meses. Além disso, conforme a aceitação do público, a peça poderia ser reprisada. (BUENO, 2012)

Outra forma de representação teatral era o Quadro Vivo, emergido na década de 1940, a representação de vida e morte de Jesus Cristo envolvia toda a comunidade em sua confecção. A encenação acontecia na Matriz de Santa Isabel na sexta-feira da paixão e a via crucis cristã, vivida pelo Quadro Vivo,foi uma das inspirações de outra importante arte na Colônia: a Via Sacra de Luiz Veganin.

\section{O sentimento através das artes plásticas}

No campo das artes plásticas, destacamos a produção do pintor Luiz Carlos de Souza, o Veganin,era um artista completo, pintor, escultor e desenhista. Ele chegou em Santa Isabel no ano de 1970. Sua personalidade ficou marcada no convívio social por sua revolta em relação à moléstia. O pseudônimo refere-se o nome de um medicamento que o artista utilizava para amenizar as fortes dores causadas pela hanseníase, o que lhe causou dependência. Era um artista solitário, gostava de aproveitar sua individualidade para gerir sua produção artística. (FUNARBE, 2010).

Segundo Bueno(2012), Veganin evitava fazer ligação entre o artista e o hanseniano, devido a traumas decorridos do processo do isolamento. Entende-se que 
ele nunca assinava suas obras, com medo de haver a identificação com sua pessoa, dessa forma suas obras eram assinadas com o nome "Espectro", uma estratégia para não atrapalhar suas vendas. ${ }^{12} \mathrm{O}$ próprio nome "espectro" revela a sombra de um fantasma, chamado estigma que acompanhava a vida do asilado.

Insurgente com os danos da doença, o artista trabalhou na marcenaria da Caixa Beneficente. Fez diversos trabalhos artísticos, entre pinturas e esculturas em madeira e pedra sabão. Considerado autodidata, tinha apenas a $4^{\mathrm{a}}$ série primária e gosto por diversos tipos de leituras de variados campos do conhecimento. (FUNARBE, 2010).

Em 1987, iniciou uma de suas maiores obras: a "Via Sacra". Ela que foi encomendada pelo pároco na época, Frei Diogo Reesink, para ser exposta nas paredes da Matriz de Santa Isabel. A Via Sacra, para o Catolicismo, consiste em um exercício no qual os fiéis rememoram, através de quatorze estações, a trajetória de vida de Jesus - desde a condenação até o Monte Calvário e sua crucificação. Veganin utilizou vários personagens de suas leituras e as adaptou ao modelo padrão de "Via Sacra" idealizado pela Igreja.

A obra apresentou um formato moderno, vislumbrando um Cristo que caminhava sobre as problemáticas sociais do século XX. Ela seguia as orientações da Carta de Puebla, um documento elaborado pela Igreja Católica em 1979. Este documento trazia debates, reflexões e apontamentos sobre as mazelas e marginalizações sofridas pelos índios e afrodescendentes na América Latina na III Conferência Geral do Episcopado Latino-americano, em Puebla, no México (FUNARBE,2010).Veganin teve como orientador Frei Francisco Vander Poel, frade holandês, que, juntamente com Frei Diogo, o ajudaram a estabelecer o padrão sequencial das estações. A partir disso, o autor formulou, por meio de sua obra um

\footnotetext{
${ }^{12}$ Entrevista concedida a André Luiz de Jesus Bueno pelo artista e ex-interno, Sebastião Martins Botelho, Betim, 16/02/2012
} 
discurso unindo sagrado e profano. Esta junção entre fé e doença encontra-se bem expresso na "V estação" (FUNARBE, 2010).

A "V estação" recorda a ajuda que Cristo recebeu de Simão, o Cirineu. Simão foi obrigado a carregar a cruz por ordens dos soldados romanos, que conduziram Jesus, já cambaleante e muito ferido, ao calvário. Nesta adaptação iconográfica, Veganin usa a inteligência espacial, utilizando a paisagem do sanatório adaptada no significado da estação, configurando a tela na Colônia, representando a Matriz de Santa Isabel e logo ao fundoo cemitério. Além disso, figurou na cena a imagem de Doutor Orestes Dinis, primeiro diretor da Colônia e das irmãs do Monte Calvário, que cuidavam dos antigos doentes. Ainda nesta estação, nota-se a presença de um grande homem, que seria o Cirineu carregando uma grande cruz invertida. A cruz faz referência a remédios, muletas, injeções e pernas mecânicas, o que sugere referência a tratamentos a doença. O personagem bíblico é conduzido por um soldado, sem braços, a entrar no portal da Colônia, a principal via de acesso. No portal temos a inscrição: Colônia Santa Isabel e a frase HIC MANEBIMUS OPTIME, que significa “aqui ficaremos bem”. Neste mesmo detalhe, a presença franciscana no antigo sanatório é representada por um frade entrando pelo portão em direção a Colônia. Outras representações, como um cavalo de madeira, fazendo lembrar o célebre cavalo de Tróia, com inscrições votem em mim, uma loba amamentando dois bebês, fazendo referência ao mito de fundação de Roma. Em todas as estações, o artista utilizou vários tipos de iconografias que ainda esperam serem desvendadas por estudos de maior profundidade (FUNARBE, 2010). 


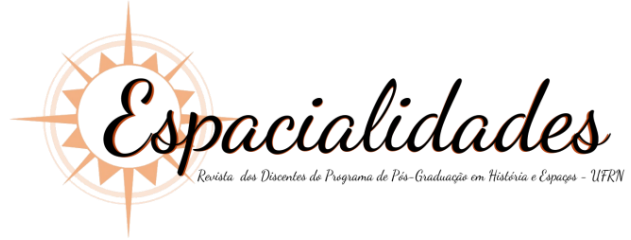

Foto 3: V - Estação da Via sacra de Luiz Veganin.

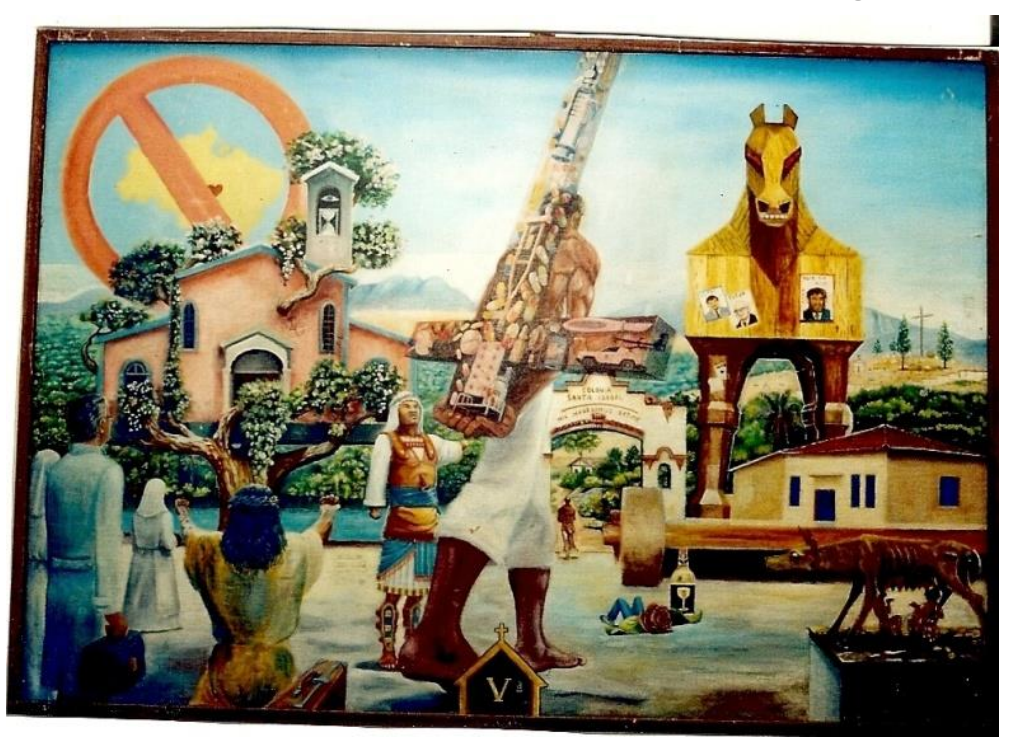

Fonte: Acervo Funarbe.

Alguns moradores da colônia, que acompanharam a confecção da Via Sacra, relataram que Veganin comentou, na época, que estava confeccionando uma obra que era "inspiração dos monstros" e a última produzida ali. Por meio de relatos coletados na colônia na época do Inventário Participativo(2010), compreende-se que tal afirmação do artista tenha relação com sua trajetória na Colônia e no acompanhamento do rumo de outros acometidos pela doença, ou seja, uma profunda crítica a vida no isolamento. Será que estavam mesmo bem e protegidos ali? Será que Deus ou a ciência olhava por eles? Já com idade avançada e muito doente, Veganin rejeitou qualquer apoio para a divulgação de seustrabalhos. Terminada a obra, ele mudou-se para a Colônia Santa Fé, em Três Corações, onde faleceu em 1997, em decorrência a complicações geradas pela doença (FUNARBE, 2010).

A obra da Via Sacra de Luiz Veganin, foi inventariada em 2009, como patrimônio cultural do município de Betim. Essa motivação se aplica na representação do artista no diálogo contextual proposto pelas estações da via crucis com a apropriação de sualigação pessoal coma doença e utilização de parte do espaço temporal que se insere a Colônia Santa Isabel como lugar de isolamento compulsório no cenário das passagens da vida de Cristo. Atualmente a obra está localizada na Matriz de Santa Isabel. 


\section{Considerações finais}

A Colônia Santa Isabel e o tema da lepra/hanseníase são temas bastante estudados, sobretudo, no campo da História das Doenças e da Saúde, no entanto, são poucas as discussões sobre sociabilidade e manifestações artísticasno interior da colônia. Pensando arte como um direito humano e como elemento fundamental na construção de outras possibilidades ver e estar no mundo.

A arte na vida do hanseniano atuou abrandando suas dores, e, também, como um refúgio, permitindo a manutenção de laços com valores exteriores em uma sociedade criada pela atuação estatal. Era uma maneira do artista-interno dizer para todos, da Colônia ou fora dela: eu existo, sou humano e a doença e a saúde fazem parte da vida de qualquer um. Seguindo fielmente um conjunto de ideias para amenizar o impacto do isolamento e da internação no Sanatório Santa Isabel, os artistas internos (os que mencionamos aqui e possivelmente outros que por lá passaram) foram influenciados pelo estigma ao gerirem suas obras, seja para esquecer o duro fardo do preconceito e das interferências na estética do corpo, seja para lembrar e comunicar a todos a superação e a reinvenção da vida na experiência do isolamento.

Assim também, a música transmitiu em sua linguagem lírica as dores e lembranças de uma sociedade que se dizia não diferir da que estava do lado de fora do isolamento da Colônia. Uma sociedade que se fez "melhor" que aquela que os excluiu. Hoje, contudo, é difícil reconhecer estes sujeitos que figuraram no período da antiga Colônia Santa Isabel, pelo simples fato das mudanças ocasionadas com a abertura do Sanatório e a ausência de políticas de proteção estatal quanto às identidades construídas na colônia. As bandas de música, os bailes, os grandes festivais, os carnavais e o teatro ficaram somente na memória dos pacientes. Há, também, certo desinteresse pelos agentes sociais atuais quanto essas manifestações. As únicas manifestações, que ainda resistem ao tempo, são o Coral Tangarás e a 
representação da Vida e Morte de Cristo na Semana Santa. Mesmo assim, estas festividades encontram-se decadentes devido à falta de apoio e estrutura.

Falar de Santa Isabel é algo que movimenta o imaginário social dos que viveram e que ainda vivem nesse território, pelo fato de que, se não fossem as fotos e memórias de alguns de seus habitantes, ninguém acreditaria que nesta sociedade se produziu cultura e arte igual a qualquer outro espaço da sociedade que isolou seus moradores. Precisamos conhecer esses indivíduos, compreendê-los para além da doença, como sujeitos históricos que reinventaram formas de vida, arte e cultura no isolamento.

\section{FONTES}

Entrevista concedida a André Luiz de Jesus Bueno pelo artista e ex-interno, Sebastião Martins Botelho, Betim, 16/02/2012.

Entrevista concedida a André Luiz de Jesus Bueno pelo antigo morador José Bueno Filho, Betim, 12/12/2012.

\section{REFERÊNCIAS}

ASSIS, Terezinha. A História da Construção de Betim, Espaço Geográfico Construído por Gente, Betim, MG, 1996.

BOSI, Alfredo. Reflexões sobre a arte. Editora Ática - São Paulo, 1986.

CARVALHO, Keila Auxiliadora. Colônia Santa Izabel: A lepra e o isolamento em Minas Gerais (1920-1960) Tese de doutorado em história - Universidade Federal Fluminense. Instituto de Ciências Humanas e Filosofia, Departamento de História, Niterói, 2012.

CARVAlHO, Paulo José de. Projeto Cururu, Indelével, a nossa história! Betim, Vol.1, Betim, MG, 2007.

CASTRO, Elizabeth Amorin.O leprosário São Roque e a Modernidade, Uma abordagem da Hanseníase na perspectiva da relação Espaço-Tempo, Curitiba, 2004. 
CHAVES, Bráulio Silva. Instituições de saúde e a idéia de modernidade em Minas Gerais na primeira metade do século XX. In: MARQUES, Rita de Cássia; SILVEIRA, Anny Jackeline Torres; FIGUEIREDO, Betânia Gonçalves. (Orgs.). História da Saúde em Minas Gerais: instituições e patrimônio arquitetônico (18081958). Barueri, SP: Minha Editora, 2011

DINIZ, Orestes. Do Isolamento da Lepra(Algumas condições para a sua eficiência) Belo Horizonte, Imprensa Oficial, 1933.

DINIZ, Orestes. Nós Também Somos Gente. (Trinta anos com os Leprosos). Rio de Janeiro, 1961.

FUNARBE, Dossiê de Tombamento - Conjunto Urbano da Colônia Santa Isabel, Betim, março/1998.

FUNARBE, Inventário de proteção do Acervo Cultural (IPAC), Betim: Funarbe, 2010.

GONTIJO, Gramont, A História da Colônia Santa Isabel, Vol.1. Betim, manuscrito, s.d.

GONTIJO, Gramont, A História da Colônia Santa Isabel, Vol.2. Betim, manuscrito, s.d.

MATOS, Joelma, Betim dos Tropeiros às engrenagens 1711-2004, Betim. Não publicado.

ROCHA e VEIGA, Ana Cecília e Alberto Nogueira. Arquitetura de Saber médico a repercussão arquitetônica e urbanística das descobertas cientificas no campo da medicina. Disponível em: wmw.hanseniase.fespmg.edu.br. Acesso em: 15 de agosto de 2011.

SANGLARD, Gisele Porto.Entre os salões e o laboratório: filantropia, mecenato e práticas científicas - Rio de Janeiro, 1920-1940. Rio de Janeiro, 2005.

TUAN, Yi-Fu. Espaço e lugar: a perspectiva da experiência. Tradução e Lívia de Oliveira. -São Paulo: DIFEL,1983. 